\title{
Geodiversidad y paisaje: un análisis de su potencial en Baja California, México
}

\author{
Ivonne Haide Posada Ayala', hposada@uabc.edu.mx², Alejandro García Gastelum², \\ Viola María Bruschi ${ }^{3}$, Miguel Agustín Téllez Duarte
}

\begin{abstract}
RESUMEN
La valoración de la geodiversidad es un instrumento importante para implementar estrategias de aprovechamiento turístico sustentable del entorno natural y cultural. Dado que la mayor parte del paisaje del Estado de Baja California en México debido a su baja densidad poblacional aún es prístino y poco impactado, posee un alto potencial para el aprovechamiento de su paisaje natural y cultural, ya que las actividades que tradicionalmente se han enfocado a la explotación de los recursos naturales, como la ganadería, agricultura, pesca y minería, han sido poco exitosas por la aridez del territorio y el impacto de los fenómenos climáticos. Por lo anterior, y considerando que el turismo de aventura y ecoturismo han comenzado a cobrar importancia como actividad económica gracias a la variedad de recursos naturales y escenarios paisajísticos y culturales del Estado, se realizó un inventario general de los principales georecursos, sus atributos, actuaciones humanas y su potencial de aprovechamiento. Para ello se dividió el territorio en tres regiones: 1) Sierras peninsulares, 2) Pendiente del Golfo de California y 3) Pendiente del Oceáno Pacífico. Se establece que Baja California tiene un gran potencial para implementar actividades productivas que giren alrededor de la conservación del paisaje. Del análisis se deduce que la figura de conservación de los geoparques es una opción para ser aplicada, ya que implica el involucramiento de la sociedad en las actividades económicas, particularmente de las comunidades rurales, donde históricamente las oportunidades de desarrollo han sido muy bajas.
\end{abstract}

Palabras clave: georecursos, geoturismo, geoparques, patrimonio natural, patrimonio cultural.

\section{Geosdiversity and landscape: an analysis of potential in Baja California, México}

\begin{abstract}
The assessment of geodiversity is an important to implement strategies for sustainable tourism development of natural and cultural environment instrument. Since most of the landscape of Baja California in México due to its low population density is still pristine and little shocked, has high potential for the exploitation of its natural and cultural landscape, and that the activities have traditionally focused exploitation of natural resources such as livestock, agriculture, fishing and mining, have been unsuccessful because the dry land and the impact of climatic phenomena. Therefore, and considering that adventure tourism and ecotourism have started to gain importance as an economic activity due to the variety of natural scenery and cultural resources and state scenarios, a general inventory of the main georesources, attributes, actions are performed human and their ability to benefit. For this, the territory was divided into three regions: 1) Peninsular Sierras, 2) Pending the Gulf of California and 3) Pending the Pacific Ocean. It was found that Baja California has great potential to implement productive activities that revolve around landscape conservation. From the analysis, it follows that the figure of conservation of Geoparks is an option to be applied, since it implies the involvement of society in economic activities, particularly in rural communities, where historically development opportunities have been very low.
\end{abstract}

Keywords: Georesources, geoturism, geoparks, natural heritage, cultural heritage.

Recibido el 3 de octubre de 2014, aceptado el 19 de diciembre de 2014.

1 Universidad Autónoma de Baja California. Instituto de Investigaciones Oceanológicas. Km 103, Autopista Tijuana-Ensenada, CP 22860, Baja California, México.

2 Universidad Autónoma de Baja California. Facultad de Ciencias Marinas.

3 Universidad de Cantabria. Facultad de Ciencias. Departamento de Ciencias de la Tierra. 


\section{INTRODUCCIÓN}

El planeta Tierra en su totalidad se comporta como un sistema vivo, donde los millones de organismos que lo habitan mantienen un equilibrio con las características abióticas que sustentan la vida (SILVA 2008). Por ello, los componentes naturales del medio ambiente conforman dos subsistemas: los de naturaleza biótica (biodiversidad) y los abióticos (geodiversidad). La relación entre ambos reside en que la biodiversidad es el resultado de billones de años de evolución y extinción, y que el registro de los fósiles nos permite conocer cómo ésta ha cambiado a través del tiempo (GRAY 2004), y cómo en nuestros días la biota se encuentra condicionada por el escenario geológico, y más específicamente por la geodiversidad, por lo que ésta es un elemento esencial del medio natural que interacciona con el resto de sus componentes y en numerosas ocasiones los condiciona (DEL RAMO JIMÉNEZ et al. 2003).

Este concepto es relativamente nuevo y su estudio aún está en desarrollo. Se han dado una gran variedad de definiciones, entre las que se encuentra: "la conexión entre gente, paisaje y cultura; es la variedad de ambientes geológicos, fenómenos y procesos que dan origen al paisaje, rocas, minerales, fósiles y suelos que proveen el marco de referencia de la vida en la tierra" (STANLEY 2000). Por tanto, partiendo de este concepto, la geodiversidad la componen los rasgos y procesos geológicos que conforman el patrimonio natural y cultural, donde el primero de ellos incluye el constituyente abiótico del medio ambiente en el que se encuentran los aspectos geológicos, como son: rocas, fósiles, suelos, minerales, agua, geomorfología, etc. (GRAY 2004), siendo así el registro de la historia del planeta y por tanto su memoria (MARTÍNEZ 2008). Se puede abreviar diciendo que el patrimonio natural comprende todos aquellos monumentos naturales, formaciones geológicas, lugares y paisajes naturales, que tienen un valor relevante desde el punto de vista estético, científico y/o medioambiental (UNESCO 1999), donde sus elementos biológicos están fuertemente vinculados con el entorno geológico, de tal forma que a su vez se puede dividir en un patrimonio biológico, plasmado en el término de biodiversidad, y un patrimonio geológico, recientemente enlazado al concepto de geodiversidad (NIETO 2001; 2002).

El patrimonio cultural es definido como la herencia tangible e intangible del pasado de una comunidad, con la que ésta vive en la actualidad y que transmite a las generaciones presentes y futuras. Son los bienes y valores que son expresiones de la nacionalidad o identidad de un pueblo. El patrimonio cultural es sumamente importante al legitimar a un grupo humano, marcar su sentido de pertenencia a la comunidad y reforzar una identidad propia (NIETO 2002), y está fuertemente ligado a la geodiversidad debido a que en el devenir histórico del paisaje geológico y sus recursos, éste ha jugado un papel muy importante en el desarrollo de la cultura, desde la prehistoria, con el uso de materiales líticos para la confección de artefactos, hasta nuestros días. La conjugación de estos aspectos que definen la geodiversidad, originando paisajes naturales, han causado en el ser humano desde un simple goce estético hasta una influencia decisiva en el desarrollo de las culturas (BRUSCHI 2007). De allí que la geodiversidad es la base en que se sustentan las interacciones entre el uso de la naturaleza y la cultura, y donde el turismo cobra importancia para el uso sostenible del paisaje (PROSSER et al. 2011). En este aspecto, el geoturismo, entendido como viajar con objeto de experimentar, aprender y disfrutar el patrimonio de la Tierra (HOSE 2000), promueve la comprensión y apreciación de las rocas, los fósiles y los accidentes geográficos (MCKIRDY et al. 2001), de manera que el visitante, además de conocer y disfrutar del patrimonio geológico, natural y cultural, contribuye a fomentar 
y estimular actividades favorables para su conservación a través del uso de bienes y servicios ofrecidos localmente en las comunidades.

Si bien existen numerosas definiciones de la geodiversidad, CARCAVILLA et al. (2008) dice que prácticamente ninguna viene acompañada de un método de estudio y análisis con la aplicación del concepto teórico a la realidad de un territorio. Aun así, la idea se ha ido expandiendo y aplicando en países como España (NIETO et al. 2006; BRUSCHI 2007), Portugal (BRILHA 2005), Italia (PIACENTE \& CORATZA 2005), Polonia (Koslowski 2004), Irlanda (MOLES \& MOLES 2004), Japón (WATANABE 2005), Brasil (PEREIRA et al. 2013), Estados Unidos (GRAY 2004; SANTUCCI 2005), entre otros, donde se han realizado diversos estudios sobre geodiversidad, sobre todo en áreas naturales protegidas, para aumentar la oferta de aprovechamiento turístico de los escenarios naturales y culturales.

En México recientemente se han comenzado a valorar los escenarios geológicos como parte del paisaje natural (GAITÁN \& ARELLANO 2009; PUY y ALQUIZAR et al. 2012). Desde el punto de vista geológico, el Estado de Baja California es uno de los sitios más relevantes en el país por su compleja historia geológica y tectónica. Su baja tasa de poblamiento ha favorecido que la mayor parte de sus escenarios naturales y culturales se encuentren en un excelente estado de conservación y con un alto potencial de aprovechamiento turístico. Por ello, el objetivo de este trabajo es hacer un inventario y descripción de los principales atributos naturales y culturales de la geodiversidad del Estado de Baja California, con la finalidad de sentar las bases para establecer instrumentos de gestión que puedan ser incorporados al aprovechamiento turístico sustentable del territorio a través de su conservación.

\section{MATERIALES Y MÉTODOS}

\section{Área de estudio}

El Estado de Baja California se localiza en la porción norte de la península de Baja California (Fig. 1), tiene una extensión territorial de $69.921 \mathrm{~km}^{2}$, que corresponden al 3,7\% de la superficie total de México. Cuenta con un litoral de 1280 $\mathrm{km}$, de los cuales $720 \mathrm{~km}$ se encuentran en la costa del Océano Pacífico y $560 \mathrm{~km}$ en la del Golfo de California. El territorio incluye $2.071 \mathrm{~km}^{2}$ repartidos en 55 islas, 37 de las cuales están en el Golfo de California y 18 en el Océano Pacífico. El clima presenta diferencias notables dadas por la orografía, latitud y oceanografía costera, siendo más templada y fría la parte noroeste, y seca y caliente la región Este y central, debido a su diversidad altitudinal, latitudinal y topográfica. La temperatura media anual oscila entre $\operatorname{los} 8^{\circ}$ y $25^{\circ} \mathrm{C}$. Los tipos de vegetación en Baja California están directamente relacionados con las características climatológicas y fisiográficas predominantes en cada una de las diferentes regiones. Éstas comprenden dos regiones fisiográficas: la región Californiana tambien llamada región Mediterránea y la región del Desierto Central o Desierto Sonorense. La Región Californiana ocupa la porción noroeste del Estado, cuenta con aproximadamente 795 géneros y 4.452 especies de plantas vasculares nativas, y las comunidades vegetales presentes en esta región son: marismas, dunas, matorral costero, chaparral y bosques de coníferas. La Región Sonorense ocupa el 70 por ciento de la península de Baja California y se distingue por la simplicidad de su composición, sobre todo en las planicies arenosas, que representan un alto porcentaje del área; sin embargo, en las partes altas de las bajadas, colinas y montañas existe una rica vegetación. En esta región se encuentra: chamizos, ocotillo, gobernadora, palo verde, palo fierro y mezquite, entre otros (DELGADILLO 1998). 


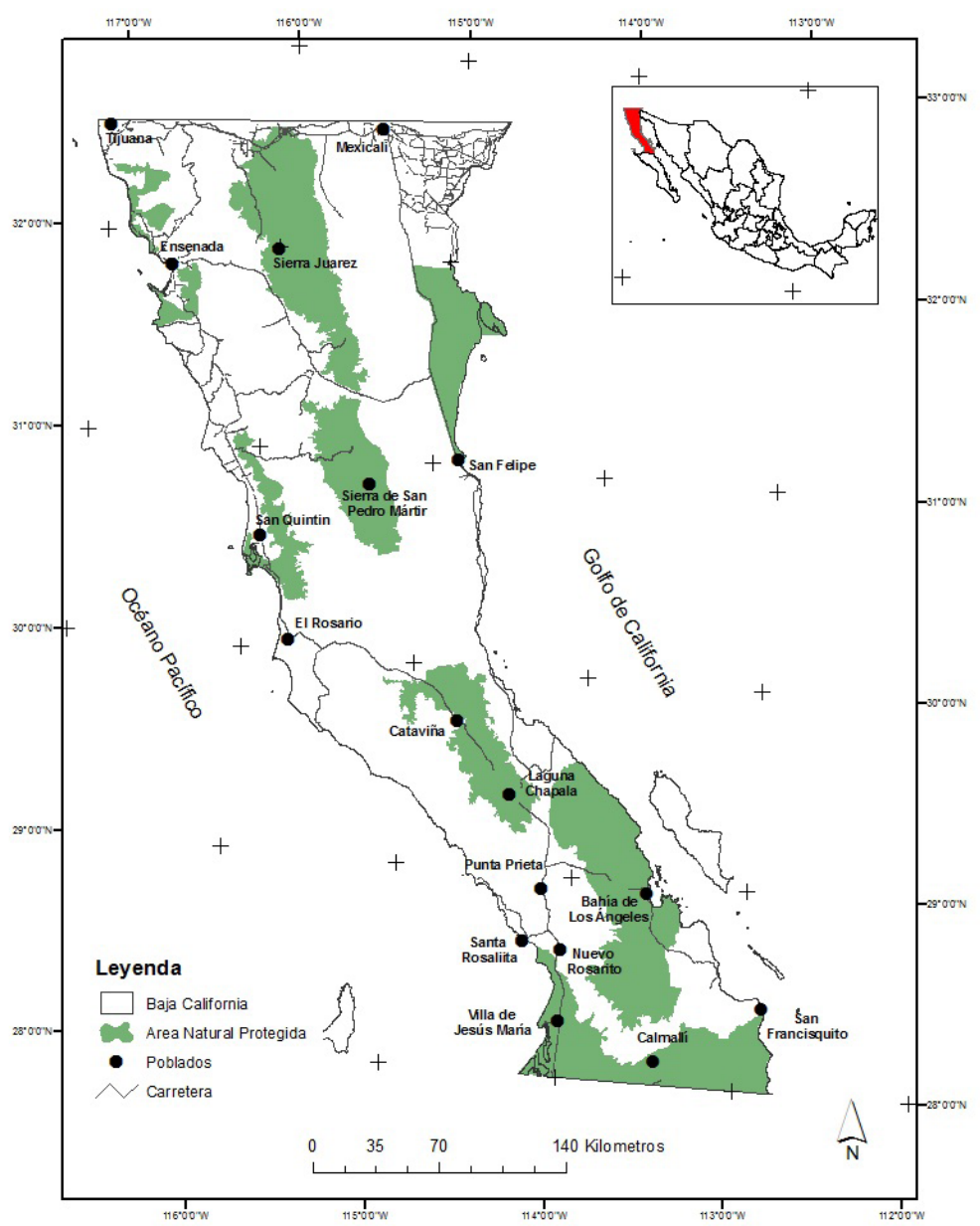

Fig 1. Mapa de localización del área de estudio.

Fig. 1. Location map of study area.

\section{Procedimientos}

Para identificar los sitios de interés geológico se consideraron las tres regiones geomorfológicas que conforman al Estado de Baja California: 1) Región de Sierras Peninsulares; 2) región de la pendiente del Golfo de California; y 3) región de la pendiente del Pacífico (Fig. 2), sobre las cuales se realizó una revisión bibliográfica para identificar localidades que revistieran importancia geológica por sus rasgos geomorfológicos, tectónicos, estructurales, estratigráficos, presencia de fósiles, como también elementos geológicos que culturalmente sean importantes por formar parte del patrimonio tangible e intangible para las comunidades locales. Una vez identificados los sitios, se realizó un recorrido de campo para verificar su ubicación y registrar fotográficamente los atributos del paisaje de interés. Con los datos se elaboró una tabla donde se describen los atributos del paisaje de los sitios de interés con mayor potencial para su aprovechamiento sustentable. 


\section{RESULTADOS}

\section{Marco geológico}

La península de Baja California formó parte del macizo continental de Norteamérica, del que se separó por procesos tectónicos que se iniciaron en el Mioceno, cuando existía una zona de subducción en la que desapareció la placa Farallón debajo de Norteamérica. Como resultado, cambió al actual régimen transtensivo que culminó con la apertura del Golfo de California a lo largo de la frontera entre las placas Pacífico y Norteamérica (STOCK 1997). En su configuración actual, geológicamente, la península se compone de tres grupos principales de rocas: 1) una franja occidental de posibles sedimentos y rocas volcánicas del Precámbrico intrusionadas por rocas graníticas del Cretácico Tardío; 2) secuencias de rocas sedimentarias marinas y volcanoclásticas en un basamento ofiolítico que fue afectado por el evento intrusivo del Cretácico Tardío; y 3) sedimentos postbatolíticos y rocas volcánicas de edades del Cretácico tardío y Cenozoico que sobreyacen a las rocas anteriores (FRIZZELL 1984). Esta diversidad de rocas y una historia geológica peculiar le confieren a la península una gran diversidad de paisajes, entre los que dominan las Sierras Peninsulares y un abrupto alto topográfico que se extiende por todo el Estado, pero que alcanza su máxima elevación en la zona norte. Los rangos de máxima altura de esta cordillera son de aproximadamente 1.800 m.s.n.m. y 3.078 m.s.n.m. en la parte norte (SEDLOCK 2003). La cadena montañosa divide a Baja California en tres regiones geomorfológicas: 1) región de Sierras Peninsulares; 2) región de la pendiente del Golfo de California; y 3) región de la pendiente del Pacífico (Fig. 2). Las características de estas regiones geomorfológicas y sus atributos geológicos y culturales (Tabla 1) se describen a continuación:

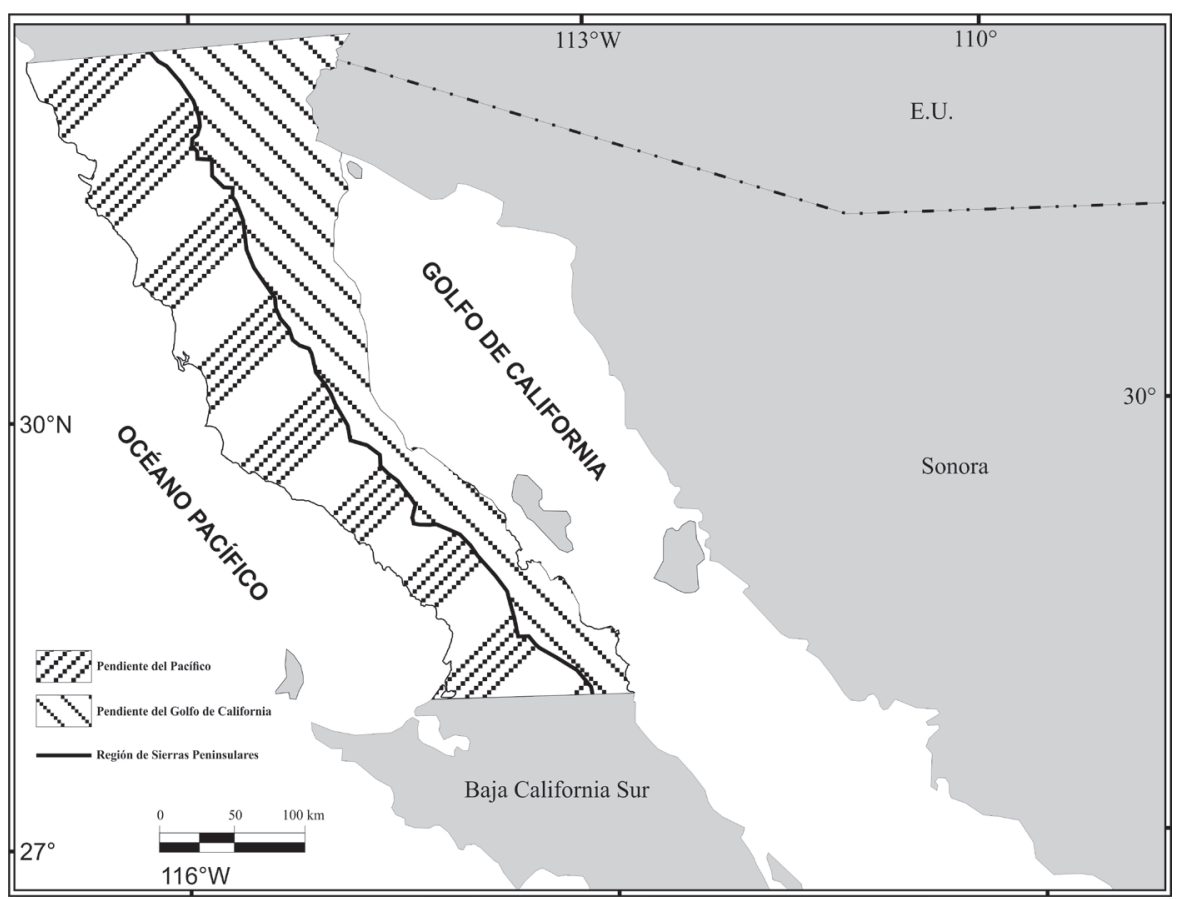

Fig. 2. La región de las Sierras Peninsulares es la división entre la pendiente del Océano Pacífico y la del Golfo de California.

Fig. 2. Region of the Peninsular Ranges is the division between the slope of the Pacific Ocean and the Gulf of California. 


\section{Región 1: Sierras Peninsulares}

Esta región geomorfológica está definida por un Batolito Mesozoico reconocido por su excepcional regularidad y por su asimetría transversal en cuanto a edades y composición (ORTEGA-RIVERA 2000). El sistema montañoso recorre prácticamente todo lo largo de la península, con pendientes a menudo muy abruptas en su vertiente hacia el Golfo de California y mucho más suaves hacia el Océano Pacífico. De norte a sur destacan la Sierra de Juárez y la Sierra de San Pedro Mártir por formar las cordilleras de mayor elevación.

Los principales tipos de rocas que las componen son graníticas (MINCH et al. 2003), y en menor proporción rocas metamórficas y metavolcánicas.

El sistema orográfico se enlaza con las montañas del sur de la Alta California y con la Sierra Nevada (RZEDOWSKI 1978). La Sierra Juárez, de aproximadamente $170 \mathrm{~km}$ de longitud, en sus partes altas florísticamente se compone de bosques de pinos y encinos, predominando el chaparral de manzanita y vara colorada, entre otras especies de arbustos. Su sitio más emblemático es el Parque Nacional Constitución, localizado entre $1.500 \mathrm{y}$ $1.800 \mathrm{~m}$ de altitud, en cuyo interior se localiza la Laguna Hanson (Fig. 3), en la que afloran espectaculares bloques de granito, en algunos de ellos con evidencias arqueológicas de haber sido utilizados como sitios de molienda.

La Sierra de Juárez continúa hacia el sur formando la sierra San Pedro Mártir, de la cual se separa por el rasgo tectónico más notable en el Estado: la Falla de Agua Blanca. En ésta se encuentra el pico de la
Encantada o Picacho del Diablo de $3100 \mathrm{~m}$ de altitud (Fig. 3), el más elevado del Estado. La sierra alberga el Parque Nacional de San Pedro Mártir, en una altitud entre $1.300 \mathrm{y}$ $3.000 \mathrm{~m}$., caracterizado por espesas zonas boscosas de pino, cedro y otras variedades maderables. Además, por la limpieza de su atmósfera se ubica el observatorio astronómico nacional de la Universidad Nacional Autónoma de México, uno de los más modernos de América Latina (DELGADILLO 1998), y desde donde, a lo largo del borde de la sierra definido por un escarpe de falla, se tienen espectaculares cantiles con vistas panorámicas del desierto de San Felipe y el Golfo de California.

En el extremo sureste, hacia el Golfo de California, se encuentran la Sierra Calamajue, San Luis, Columbia, San Borja y Calmallí (AGUIRRE 1987). Este último fue un importante distrito minero que tuvo su apogeo en el siglo XIX, existiendo en toda el área ruinas y vestigios mineros de gran atractivo geoturístico, especialmente el Distrito de Calmallí que es rico en recursos naturales y culturales, incluyendo en estos últimos, pintura rupestre monumental en resguardos rocosos y la Misión de Santa Gertrudis, uno de los edificios coloniales de cantera de toba mejor conservados de toda la península.

En su conjunto estas sierras componen un área natural casi intacta que conecta a dos países y algunos de los más ricos ecosistemas de montaña y del desierto en el mundo, en el que prosperan especies emblemáticas como el puma, el cóndor de California (Gymnogyps californianus), el águila real (Aquila chrysaetos) y el borrego cimarrón (Ovis canadensis) (TIERRA PENINSULAR 2004). 


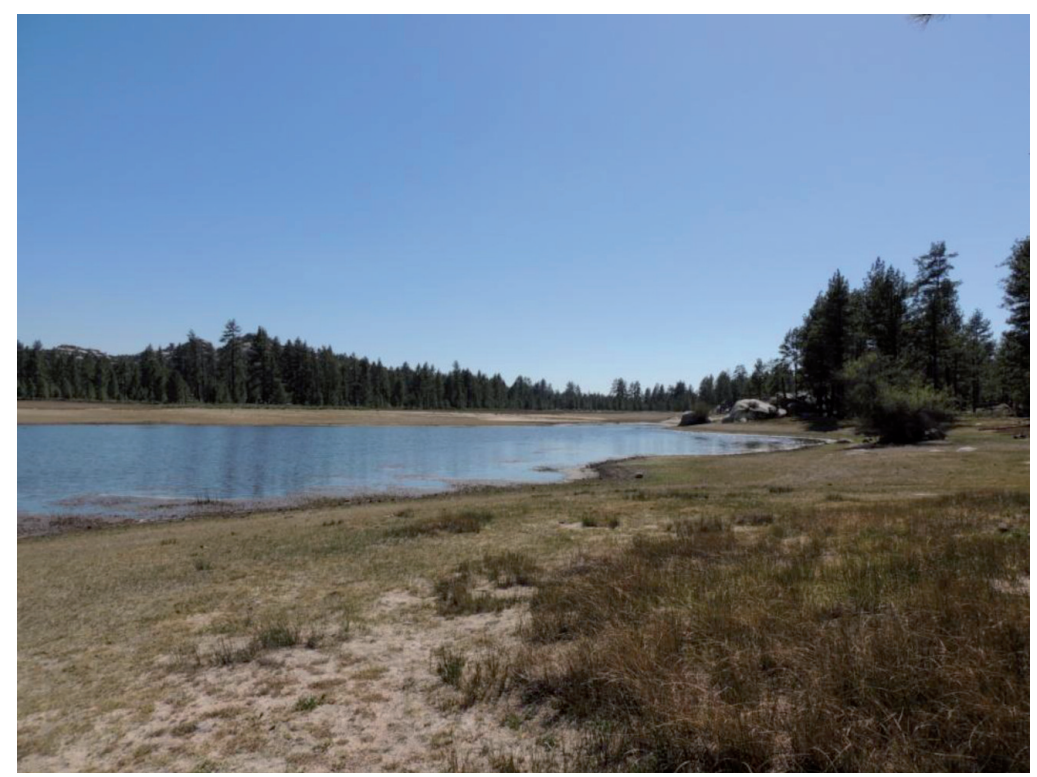

Fig. 3. Laguna Hanson, en la Sierra Juárez.

Fig. 3. Hanson Lake in the Sierra Juárez.

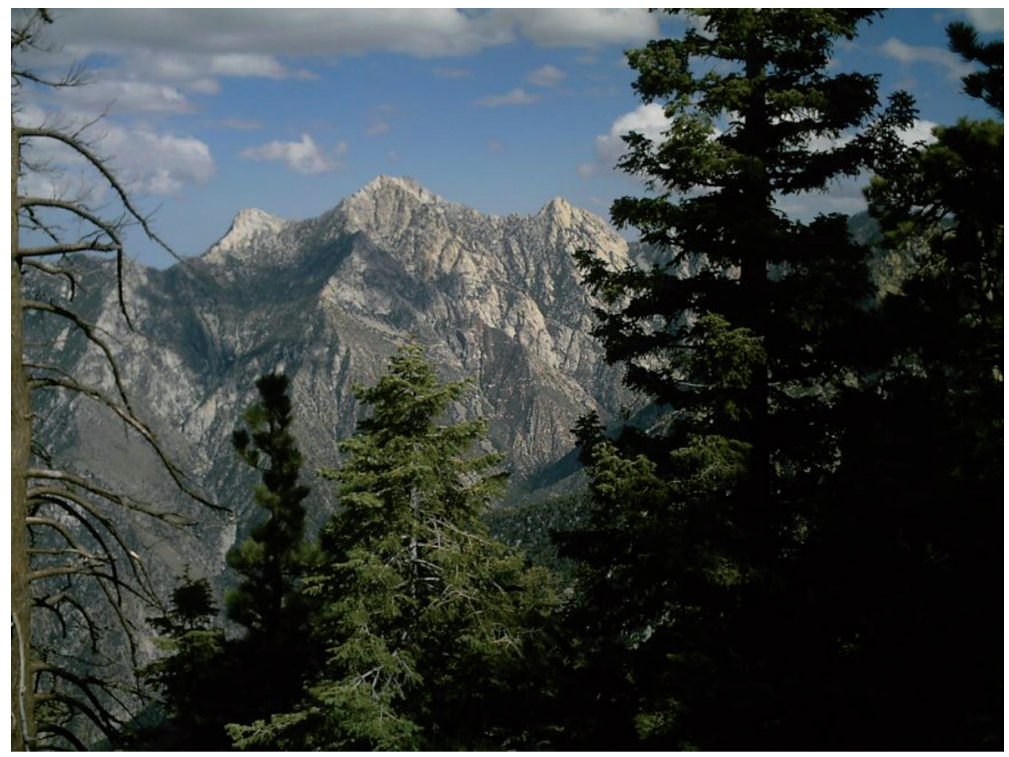

Fig. 4. Panorámica del Picacho del Diablo, en la Sierra de San Pedro Mártir.

Fig. 4. Overview of Picacho del Diablo, in the Sierra de San Pedro Mártir. 
Tabla 1. Principales rasgos geológicos y culturales que conforman la geodiversidad de los poblados de la región 1 en el Estado de Baja California, así como las actividades SUSTENTABLES FACTIBLES DE IMPLEMENTAR COMO COMPLEMENTO A LAS YA EXISTENTES. SOLO SE INCLUYEN LAS ÁREAS MÁS IMPORTANTES POR SU ACCESIBILIDAD.

Table 1. Major geological and Cultural features that MaKe the geOdiVersity OF the VILlages

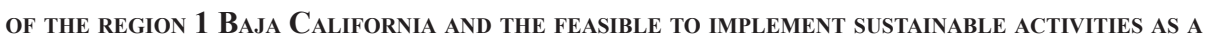
COMPLEMENT TO EXISTING. ONLY THE MOST IMPORTANT AREAS ARE INCLUDED FOR THEIR ACCESSIBILITY.

\begin{tabular}{|c|c|c|c|c|c|}
\hline Poblado & Atributos paisajísticos & Atributos culturales & Vegetación & $\begin{array}{l}\text { Actuaciones } \\
\text { humanas }\end{array}$ & $\begin{array}{l}\text { Potencial de } \\
\text { aprovecha- } \\
\text { miento }\end{array}$ \\
\hline $\begin{array}{l}\text { Sierra de } \\
\text { Juárez }\end{array}$ & $\begin{array}{c}\text { Cadena montañosa } \\
\text { del batolito peninsular } \\
\text { del Cretácico; bloques } \\
\text { graníticos expuestos, } \\
\text { ciénegas y una laguna } \\
\text { semi-permanente. }\end{array}$ & $\begin{array}{c}\text { Numerosos sitios } \\
\text { arqueológicos de la } \\
\text { prehistoria tardía con } \\
\text { pintura rupestre y cam- } \\
\text { pamentos estacionales. } \\
\text { Minas abandonadas. }\end{array}$ & $\begin{array}{l}\text { Bosque de } \\
\text { pino-encino } \\
\text { y chaparral. }\end{array}$ & $\begin{array}{c}\text { Explotación } \\
\text { forestal y ga- } \\
\text { nadera, minería } \\
\text { y ecoturismo } \\
\text { incipiente. Un } \\
\text { área protegida } \\
\text { como Parque } \\
\text { Nacional. }\end{array}$ & $\begin{array}{l}\text { Geoturismo, } \\
\text { ecoturismo, } \\
\text { senderismo, es- } \\
\text { calada en roca, } \\
\text { campismo. }\end{array}$ \\
\hline $\begin{array}{l}\text { Sierra } \\
\text { de San } \\
\text { Pedro } \\
\text { Mártir }\end{array}$ & $\begin{array}{c}\text { Espectaculares cañones } \\
\text { de rocas graníticas } \\
\text { y metamórficas del } \\
\text { batolito peninsular del } \\
\text { Cretácico, el pico mon- } \\
\text { tañoso más alto de la } \\
\text { península. }\end{array}$ & $\begin{array}{l}\text { Pictografía y grabados } \\
\text { rupestres, ruinas de la } \\
\text { Misión de San Pedro } \\
\text { Mártir de Verona. } \\
\text { Minas abandonadas. }\end{array}$ & $\begin{array}{l}\text { Bosque de } \\
\text { pino-encino } \\
\text { y chaparral. } \\
\text { Especies } \\
\text { endémicas } \\
\text { de flora. }\end{array}$ & $\begin{array}{l}\text { Ganadería, eco- } \\
\text { turismo incipien- } \\
\text { te. Observatorio } \\
\text { Astronómico } \\
\text { Nacional y Par- } \\
\text { que Nacional. }\end{array}$ & $\begin{array}{l}\text { Geoturismo, } \\
\text { ecoturismo, } \\
\text { senderismo, es- } \\
\text { calada en roca, } \\
\text { campismo. }\end{array}$ \\
\hline Calmallí & $\begin{array}{l}\text { Rocas volcánicas con } \\
\text { minerales de cobre. }\end{array}$ & $\begin{array}{l}\text { Abundan vestigios } \\
\text { mineros principalmen- } \\
\text { te en El Arco, Pozo } \\
\text { Alemán y el Cañón de } \\
\text { de Calmallí. Pintura } \\
\text { rupestre estilo Gran } \\
\text { Mural y la misión de } \\
\text { Santa Gertrudis. }\end{array}$ & $\begin{array}{l}\text { Vegetación } \\
\text { desértica } \\
\text { con áreas } \\
\text { extensas } \\
\text { de cardón } \\
\text { y algunos } \\
\text { cañones con } \\
\text { palmeras. }\end{array}$ & $\begin{array}{l}\text { Ganadería, nu- } \\
\text { merosas minas } \\
\text { abandonadas. } \\
\text { Está en proyecto } \\
\text { reabrir la mina } \\
\text { de El Arco. }\end{array}$ & $\begin{array}{l}\text { Geoturismo } \\
\text { minero, ecotu- } \\
\text { rismo, turismo } \\
\text { histórico y } \\
\text { arqueológico, } \\
\text { senderismo, } \\
\text { campismo. }\end{array}$ \\
\hline
\end{tabular}

\section{Región 2: Pendiente del Golfo de California}

Cuando la dorsal del Pacífico pasó bajo el continente e inició la apertura del actual Golfo de California, originó el levantamiento de la península como una serie de bloques inclinados y fallados que conforman las serranías costeras del Golfo de California (MINCH et al. 2003). La vertiente oriental de la península se caracteriza por la presencia de bajadas con lomeríos, declives de sierras, mesetas disectadas con cañadas, sierras bajas y sierras bajas con mesetas (LÓPEZ \& MATA 2002). Esto se debe a que el sistema orográfico de Baja California presenta una fuerte orientación hacia el Golfo de California (ULLOA et al. 2006). Presenta 
unidades graníticas del Cretácico y rocas volcánicas del Terciario $\mathrm{y}$ en menor cantidad rocas sedimentarias del Terciario (MINCH et al. 2003).

Al norte del Estado se encuentra el Valle de Mexicali, conformado por aluviones depositados por las avenidas del río Colorado que originan la zona agrícola más importante del Estado, tanto por el aprovechamiento de aguas derivadas del río como por numerosos pozos profundos (AGUIRRE 1987). Limitado al sur por las sierras El Mayor y Cucapá (Fig. 5), el valle es parte de la provincia tectónica de la depresión de Salton, donde se encuentra la frontera entre las placas Pacífico y Norte América. En el Valle de Mexicali, este límite lo demarca la falla que conecta la falla de Cerro Prieto e Imperial originando una zona tensional o cuenca pull-apart denominada Cerro Prieto (ELDERS et al. 1984; LIPPMANN et al. 1984; SUÁREZVIDAL et al. 2008; SARYCHIKHINA et al. 2011). En ella sobresale el volcán Cerro Prieto (Fig. 5), donde se localiza el campo geotermal más grande de México (SARYCHIKHINA et al. 2011) y el segundo más grande del mundo, sólo superado por The Geysers en California (GUTIÉRREZ NEGRÍN \& QUIJANOLEÓN 2004). Este cono volcánico cuaternario, además de ser único en el área, es un importante geosímbolo prehispánico durante las exploraciones españolas del siglo XVIII, dada su notoriedad en medio del paraje que lo rodea. El volcán es una manifestación de la falla geológica del mismo nombre, y la principal falla activa que ocasiona los frecuentes temblores en la ciudad de Mexicali y zonas circunvecinas. En la cultura popular de la etnia Cucapá, simboliza la huella agonizante del monstruo acuoso del mito de "El muchacho travieso", donde la cita "El animal se revuelca. Luego regresa, pero ahí está la grasa hirviendo, ahí todos la pueden ver, el que quiere puede ir a verla", hace referencia a los volcanes de lodo hirviente de la Laguna Vulcano localizada en el área del volcán (OCHOA 1980, en TAPIA LANDEROS 2002).

Partiendo de la desembocadura del Río Colorado, desde el extremo norte del golfo, hasta el Puerto de San Felipe (Fig. 6), el paisaje costero lo conforman bahías, extensas planicies de mareas, salinas naturales, cordilleras compuestas de conchas de moluscos y dunas principalmente. Algunos altos topográficos, como Cerro El Moreno, Cerro Lágrimas de Apache y El Chinero, son geosímbolos importantes en la cultura popular (AMORÓS ZAVALA 2011). Más al sur, el corredor turístico San Felipe-San Luis Gonzaga, localizado en la provincia fisiográfica denominada Llanura Sonorense, subprovincia Desierto de Altar, se caracteriza por llanuras y planicies amplias con una altitud inferior a los 200 m.s.n.m. y pendientes menores del $2 \%$. En el paisaje dominan las rocas volcánicas terciarias, con algunos afloramientos de rocas metasedimentarias. En éstas sólo se conoce un sitio con fósiles paleozoicos, los cuales son de gran importancia científica y biogeográfíca por relacionarse con las rocas paleozoicas del Estado de Sonora. Otro rasgo geomorfológico que destaca en el paisaje son los campos de dunas (Fig. 7).

Al sur del delta del río Colorado hasta los límites del Estado, dominan las rocas volcánicas terciarias relacionadas con la apertura del Golfo de California, las que ocasionalmente se asocian a rocas sedimentarias fosilíferas de las primeras invasiones marinas durante la apertura del Golfo de California (MARTÍN et al. 1993). Destacan las localizadas en Puertecitos y Bahía de Los Ángeles, en cuyos alrededores también son comunes las evidencias arqueológicas (RITTER 1998). 


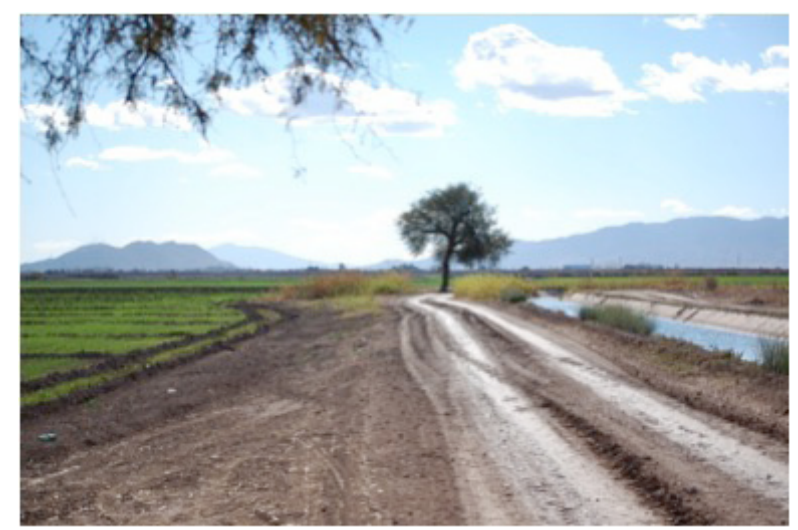

Fig. 5. Valle agrícola de México, de izquierda a derecha, el volcán Cerro Prieto y las sierras EI Mayor y Cucapá, al fondo.

Fig. 5. Agricultural Valley of México with, from left to right, the Cerro Prieto volcano and the Sierra el Mayor and the bottom Cucapá.

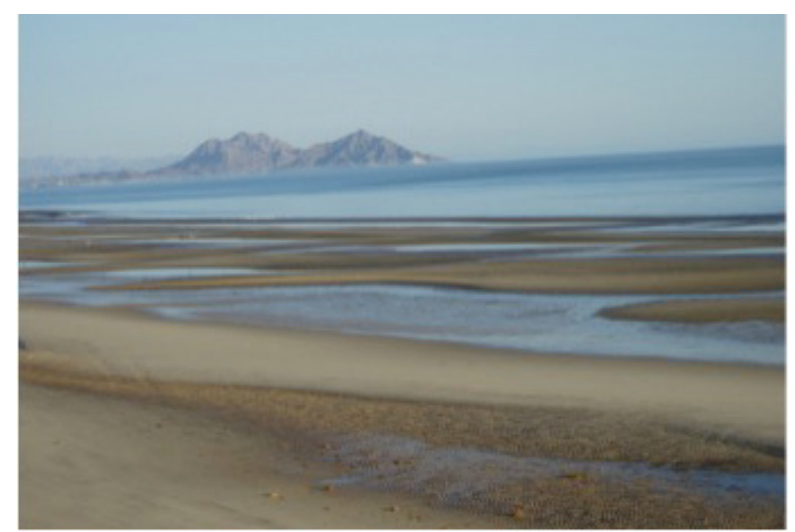

Fig. 6. Vista de las playas de San Felipe.

Fig. 6. View of San Felipe beach.

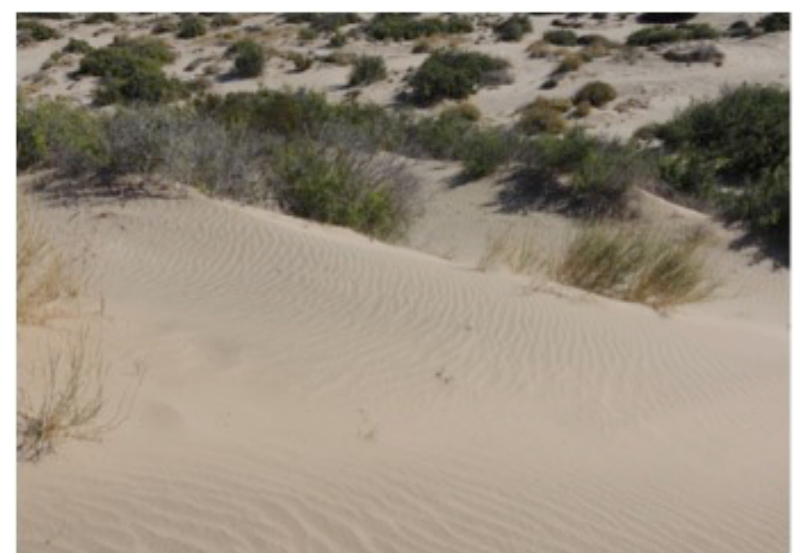

Fig. 7. Campo de dunas de San Felipe.

Fig. 7. San Felipe sand dune field. 
Tabla 2. Principales rasgos geológicos y Culturales Que Conforman la GeOdiversidad de los poblados de la Región 2 en el Estado de Baja California, así como las aCtividades SUSTENTABLES FACTIBLES DE IMPLEMENTAR COMO COMPLEMENTO A LAS YA EXISTENTES. Sólo SE INCLUYEN LAS ÁREAS MÁS IMPORTANTES POR SU ACCESIBILIDAD.

Table 2. Major geological and CUltural features that MaKe the geOdiversity OF THE VILlages

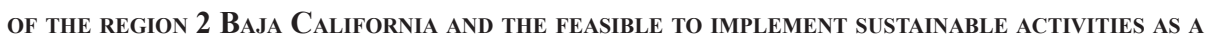
COMPLEMENT TO EXISTING. ONLY THE MOST IMPORTANT AREAS ARE INCLUDED FOR THEIR ACCESSIBILITY.

\begin{tabular}{|c|c|c|c|c|c|}
\hline Poblado & Atributos paisajísticos & $\begin{array}{l}\text { Atributos cultu- } \\
\text { rales }\end{array}$ & Vegetación & $\begin{array}{c}\text { Actuaciones } \\
\text { humanas }\end{array}$ & $\begin{array}{c}\text { Potencial de } \\
\text { aprovecha- } \\
\text { miento }\end{array}$ \\
\hline $\begin{array}{l}\text { San } \\
\text { Felipe }\end{array}$ & $\begin{array}{c}\text { Playas arenosas con ex- } \\
\text { tensos campos de dunas, } \\
\text { puntas rocosas, terrazas } \\
\text { marinas del Pleistoceno } \\
\text { con fósiles de moluscos; } \\
\text { rocas del Mioceno ma- } \\
\text { rino del protogolfo y del } \\
\text { Plioceno, muy fosilíferas. } \\
\text { Sierras de granito y rocas } \\
\text { volcánicas. Rocas meta- } \\
\text { mórficas paleozoicas. }\end{array}$ & $\begin{array}{l}\text { Concheros arqueo- } \\
\text { lógicos, sitios histó- } \\
\text { ricos de principios } \\
\text { del siglo XX. }\end{array}$ & $\begin{array}{l}\text { Vegetación } \\
\text { típica del } \\
\text { desierto } \\
\text { sonorense } \\
\text { (chamizos, } \\
\text { ocotillo, } \\
\text { gobernadora, } \\
\text { palo verde, } \\
\text { palo fierro } \\
\text { y mezquite, } \\
\text { entre otros). }\end{array}$ & $\begin{array}{c}\text { Buena parte de la } \\
\text { zona costera para } \\
\text { uso residencial y } \\
\text { turístico; dunas } \\
\text { destruidas por de- } \\
\text { sarrollos turísti- } \\
\text { cos abandonados } \\
\text { y uso excesivo } \\
\text { de vehículos todo } \\
\text { terreno. }\end{array}$ & $\begin{array}{l}\text { Ecoturismo, } \\
\text { senderismo, } \\
\text { actividades } \\
\text { acuáticas en } \\
\text { general. }\end{array}$ \\
\hline $\begin{array}{c}\text { Valle de } \\
\text { Mexicalli }\end{array}$ & \begin{tabular}{|} 
Valle conformado por \\
rellenos aluviales del río \\
Colorado. Limitado al \\
oeste por la sierra Cucapá \\
y El Mayor, formadas \\
de rocas graníticas y \\
metamórficas. Destaca el \\
volcán de Cerro Prieto. \\
Relictos de afluente del río \\
Colorado en río Hardy. \\
\end{tabular} & $\begin{array}{l}\text { Ruta histórica de } \\
\text { Anza, sitios arqueo- } \\
\text { lógicos de cam- } \\
\text { pamentos y grafía } \\
\text { rupestre. Edificios } \\
\text { históricos del siglo } \\
\text { XX. Artesanía } \\
\text { nativa cucapá. }\end{array}$ & $\begin{array}{l}\text { Vegetación } \\
\text { desértica. Ri- } \\
\text { beras del río } \\
\text { fuertemente } \\
\text { deforestadas. }\end{array}$ & $\begin{array}{c}\text { Mayor parte del } \\
\text { valle modificado } \\
\text { a uso agrícola } \\
\text { extensivo. Ins- } \\
\text { talaciones de la } \\
\text { geotérmica de } \\
\text { Cerro Prieto im- } \\
\text { pactan el paisaje. }\end{array}$ & $\begin{array}{c}\text { Geoturismo y } \\
\text { senderismo en } \\
\text { las sierras y } \\
\text { Cerro Prieto. } \\
\text { Turismo ar- } \\
\text { queológico en } \\
\text { sierra Cucapá. } \\
\text { Ecoturismo y } \\
\text { kayak en río } \\
\text { Hardy. } \\
\end{array}$ \\
\hline $\begin{array}{c}\text { San } \\
\text { Francisco }\end{array}$ & $\begin{array}{l}\text { Rocas ígneas intrusivas y } \\
\text { extrusivas. Rocas sedi- } \\
\text { mentarias fosilíferas del } \\
\text { Plioceno. Playas areno- } \\
\text { sas y rocosas } \\
\end{array}$ & $\begin{array}{l}\text { Extensos concheros } \\
\text { arqueológicos. }\end{array}$ & $\begin{array}{l}\text { Vegetación } \\
\text { desértica } \\
\text { escasa. }\end{array}$ & $\begin{array}{l}\text { Infraestructura } \\
\text { turística en la } \\
\text { zona de playa. }\end{array}$ & $\begin{array}{l}\text { Geoturismo, } \\
\text { kayak, pesca } \\
\text { deportiva, } \\
\text { buceo. }\end{array}$ \\
\hline $\begin{array}{l}\text { Bahía } \\
\text { de Los } \\
\text { Ángeles }\end{array}$ & $\begin{array}{l}\text { Sierra de granito con } \\
\text { extensos abanicos alu- } \\
\text { viales que llegan a la } \\
\text { costa. Rocas volcánicas } \\
\text { y sedimentarias con } \\
\text { fósiles abundantes de } \\
\text { moluscos. Humedales, } \\
\text { playas de arena, grava } \\
\text { y rocas, dunas costeras. } \\
\text { Islas e islotes en el paisa- } \\
\text { je marino. }\end{array}$ & $\begin{array}{l}\text { Uno de los sitios } \\
\text { en el Estado con } \\
\text { mayor número de } \\
\text { sitios histórico-cul- } \\
\text { turales de diferentes } \\
\text { periodos, desde la } \\
\text { prehistoria hasta el } \\
\text { siglo XX. Minas, } \\
\text { misiones, pinturas } \\
\text { rupestres, campa- } \\
\text { mentos y concheros } \\
\text { prehistóricos en las } \\
\text { cercanías. }\end{array}$ & $\begin{array}{l}\text { Matorral } \\
\text { sarcocaule } \\
\text { y sarco- } \\
\text { cracicaule. } \\
\text { Vegetación } \\
\text { desértica, } \\
\text { cirio, cardón, } \\
\text { torote. }\end{array}$ & $\begin{array}{c}\text { Campos turísticos } \\
\text { en buena parte de } \\
\text { la zona costera. } \\
\text { Ganadería, turis- } \\
\text { mo y pesca de- } \\
\text { portiva y comer- } \\
\text { cial, ecoturismo } \\
\text { (observación de } \\
\text { aves, mamíferos } \\
\text { marinos y tiburón } \\
\text { ballena). }\end{array}$ & $\begin{array}{l}\text { Geoturismo } \\
\text { minero, ecotu- } \\
\text { rismo, turismo } \\
\text { histórico y } \\
\text { arqueológico, } \\
\text { senderismo, } \\
\text { campismo, } \\
\text { kayak, buceo, } \\
\text { pesca depor- } \\
\text { tiva, deportes } \\
\text { acuáticos. }\end{array}$ \\
\hline
\end{tabular}




\section{Región 3: Pendiente del Océano Pacífico}

Desde la frontera hasta la parte media del Estado, el paisaje costero es dominado por rocas sedimentarias del Cretácico (Fig. 8), así como por terrazas del Pleistoceno. La vegetación también presenta un cambio muy notable, con árboles leñosos enanos $\mathrm{y}$ arbustos cubriendo colinas y pendientes, dominando el Matorral Costero y Rosetófilo, en su mayor parte en excelente estado de conservación (MINCH et al. 2003). La región noroccidental del Estado está compuesta por un basamento formado por rocas graníticas y una secuencia de rocas volcánicas, metamórficas y volcanosedimentarias del arco de la Formación Alisitos del Cretácico (Fig. 9). A su vez, sobre éste descansan discordantemente depósitos sedimentarios pobremente consolidados de la Formación Rosario del Cretácico Tardío (DELGADO 2000). Durante el Paleoceno se erosionaron los volcanes y la costa noroccidental de Baja California fue objeto de levantamientos tectónicos que dieron origen a una serie de terrazas marinas expuestas en diversas partes de la costa (GASTIL et al. 1975).

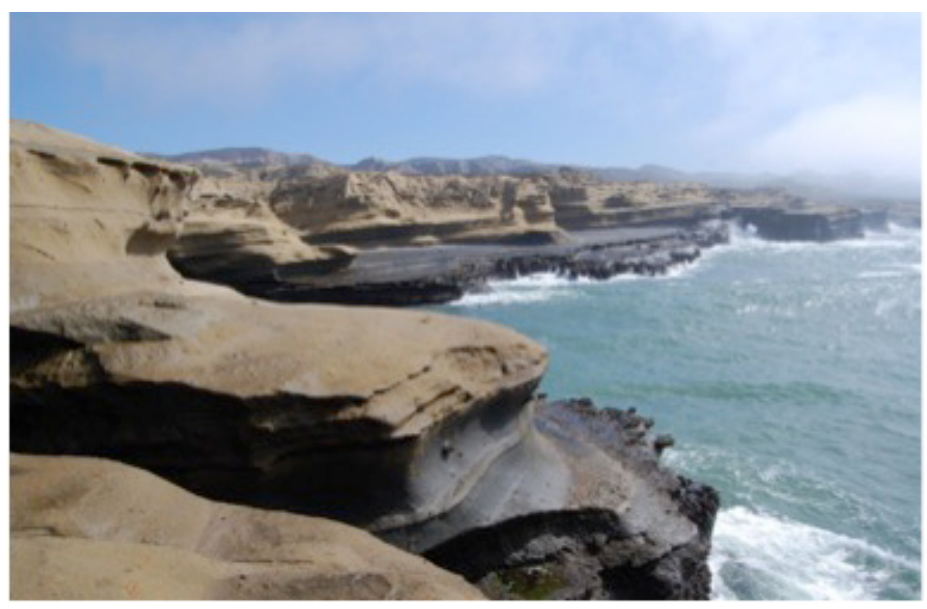

Fig. 8. Rocas sedimentarias del Cretácico, en la costa Pacífico.

Fig. 8. Cretaceous sedimetary rocks on the Pacific coast.

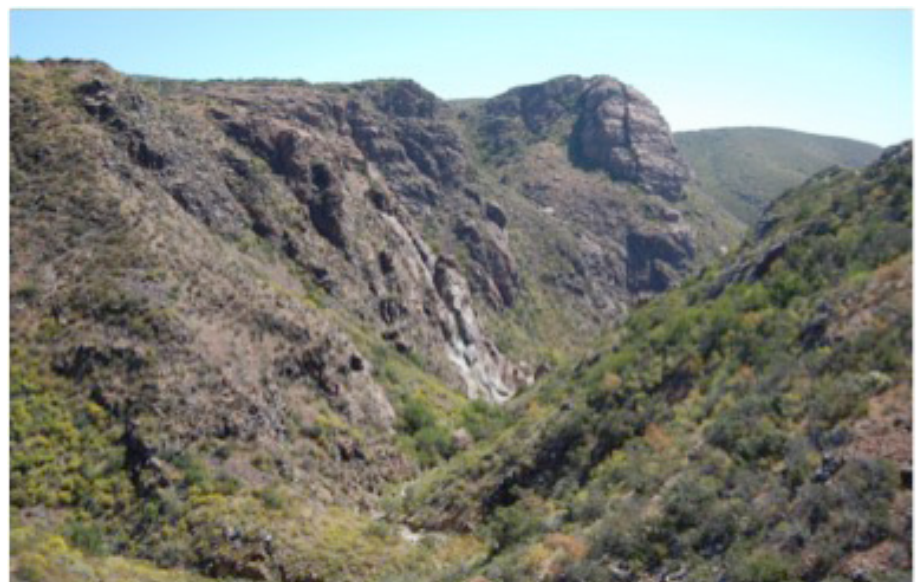

Fig. 9. Rocas volcánicas cretácicas del arco Alisitos en la región costera de la pendiente del Pacífico.

Fig. 9. Alisitos cretaceous volcanic arc rocks in the coastal region on the pacific slope. 
Por su importancia geológica y paleontológica destacan los sedimentos del Mioceno Medio de la Formación Rosarito Beachal Sur de Tijuana. Estos sedimentos fueron definidos por primera vez por MINCH (1967) como una serie de basaltos, tobas y sedimentos volcanoclásticos. Los sedimentos volcanoclásticos contienen una diversa y abundante fauna de moluscos, peces óseos y cartilaginosos, mamíferos marinos y más raramente mamíferos continentales (MINCH et al. 1984). La Formación San Diego, del Plioceno, cubre discordantemente a la Formación Rosarito Beach. También es altamente fosilífera, dominando moluscos como los bivalvos extintos Pecten healeyi, Anadara trilineata y Chalmysparmeleei, así como el gasterópodo Acanthina emersoni (ALLISON et al. 1970). Muchas de las localidades fosilíferas dentro de la ciudad de Tijuana se han perdido por el crecimiento urbano, restando algunas que ameritan su conservación, como es el caso de la localidad de La Joya. En esta misma área en la zona costera se encuentran expuestas terrazas marinas y depósitos continentales del Pleistoceno, siendo notorios los depósitos fosilíferos de Playas de Tijuana. Sobre estas terrazas abundan intermitentemente depósitos arqueológicos de concheros aborígenes, los cuales se extienden prácticamente por toda la costa del Pacífico, y que en algunos casos se han datado hasta de 9000 años de antigüedad (MINCH et al. 2003).

Al sur de Tijuana, en la Bahía Todos Santos, donde está la ciudad de Ensenada, hay una de las zonas pobladas de mayor geodiversidad. Dentro del área de la bahía afloran estratos volcánicos pre-batolíticos de andesitas a dacitas y tobas líticas cristalinas de la Formacion Alsitos. El muelle del Puerto de Ensenada fue construido con estas rocas. La franja costera de la ciudad se compone de playas arenosas, dunas y una laguna de agua dulce estacional, denominada La Lagunita, además de la laguna costera Estero de Punta Banda, que separa la bahía por una barra arenosa unida a la península de Punta Banda. Este rasgo morfológico se originó por el desplazamiento lateral-derecho de la Falla de Agua Blanca, el rasgo tectónico más sobresaliente en el norte del Estado, y en cuya traza costera afloran aguas termales y son visibles los rasgos fisiográficos que identifican a una falla geológica, por lo que además de su valor paisajístico, posee un alto valor didáctico. En los cantiles costeros de Punta Banda existe un arrecife fósil único (Fig. 10), compuesto del rudistacretácico Coralliocama orcutti, (WHITE 1885), así como una diversa fauna de otros moluscos (DEMERÉ et al. 1984). Más al sur, la localidad de Punta China dentro de la Bahía de Santo Tomás, alberga calizas arrecifales de rudistas de la Formación Alisitos del Cretácico Superior (SANTILLÁN \& BARRERA 1930), de las que se ha descrito una abundante fauna de moluscos (ALLISON 1974). Desafortunadamente, buena parte de las localidades importantes han desaparecido por la industria minera para la obtención de cemento.

Al sur, en la bahía de San Quintín existe un campo volcánico costero único en la costa del Pacífico (Fig. 11), el cual conforma y dio origen a la laguna costera durante el Pleistoceno. Además del bello escenario natural, elárea es un refugio de aves acuáticas durante el invierno, posee importantes depósitos de moluscos y mamíferos del Pleistoceno, dunas, y abundan depósitos arqueológicos diseminados en toda el área. Inmediatamente al sur de la bahía destaca en el paisaje el campo de dunas fósiles y activas, en la localidad de El Socorro. Después de ésta dominan los cantiles costeros de rocas sedimentarias cretácicas, afamadas por sus amonitas gigantes. Particularmente importante es El Rosario, donde además de la fauna marina se han hecho importantes hallazgos de dinosaurios y otros reptiles del Cretácico, además de mamíferos primitivos y abundante madera petrificada (MORRIS $1967 ; 1971)$, en un paisaje geomorfológico caracterizado por una topografía de tierras malas. En el aspecto cultural, un atractivo del área son las ruinas misionales del siglo XVIII edificadas con adobe. 
Desde El Rosario hasta los límites del Estado, dentro del Desierto Central, abundan en la zona costera paisajes compuestos de rocas del Cretácico sobre las que suprayacen rocas del Paleoceno de la Formación Sepultura. Estas son extremadamente fosilíferas, particularmente en Mesa La Sepultura, y en algunos casos los fósiles de moluscos aún poseen la concha original, como en Mesa San Carlos. En facies más costeras, localmente suelen aparecer densas concentraciones de troncos de árboles petrificados, como en
Faro San José, y en Lomas Tetas de Cabra; en las facies continentales se han reportado fósiles de mamíferos terrestres (NOVACEK et al. 1991). En general, el Desierto Central representa lo más espectacular del paisaje por su rica flora desértica, en la que destacan el cardón (Pachycereus pringlei) y el icónico cirio (Fouqueria columnaris). Culturalmente concentra una gran cantidad de sitios arqueológicos, destacando el arte rupestre, particularmente en Las Pintas, Cataviña, Montevideo y Mesa del Carmen.

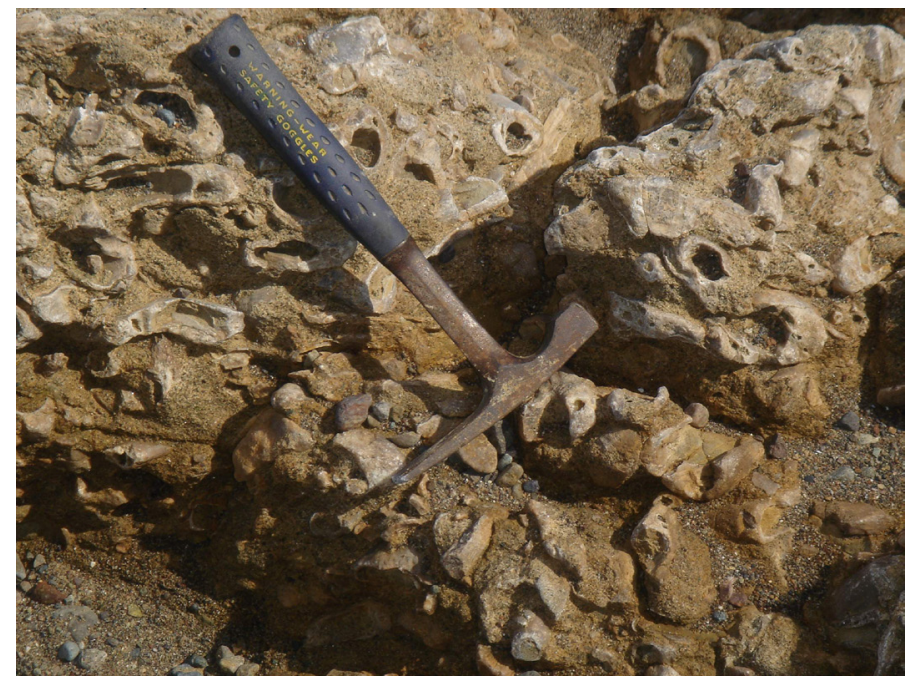

Fig. 10. Arrecifes de rudistas del Cretácico Coralliocama orcutti (WHITE, 1885).

Fig. 10. Cretaceous rudist reefs Coralliocama orcutti (WHITE, 1885).

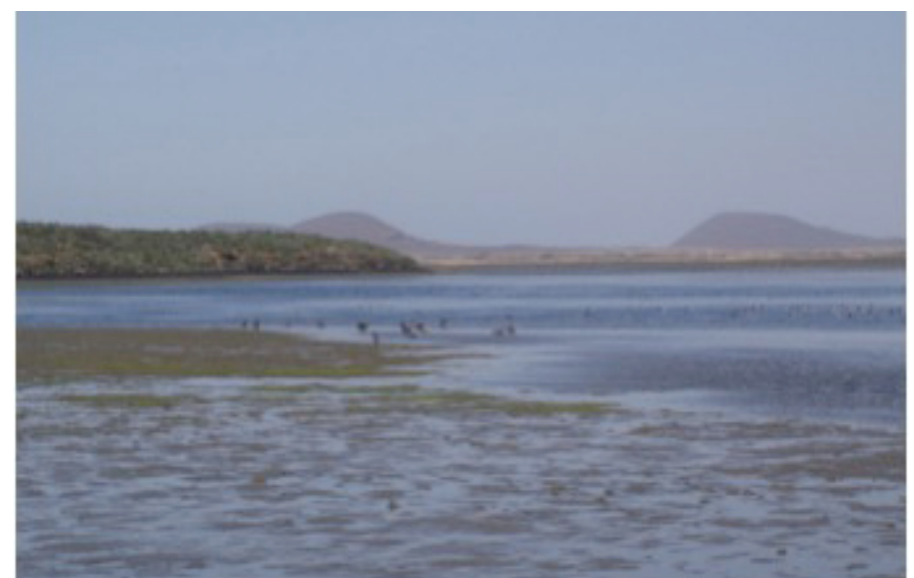

Fig. 11. Panorámica de la Bahía San Quintín, con gansos canadienses en primer plano y los volcanes al fondo.

Fig. 11. Overview of San Quintin Bay, with Canada geese in the foreground an the volcanoes in the background. 
Tabla 3. Principales rasgos geológicos y culturales que conforman la geodiversidad de los poblados de la Región 3 en el Estado de BaJa California, así como las aCtividades SUSTENTABLES FACTIBLES DE IMPLEMENTAR COMO COMPLEMENTO A LAS YA EXISTENTES. Sólo SE INCLUYEN LAS ÁREAS MÁS IMPORTANTES POR SU ACCESIBILIDAD.

Table 3. Major geological and cultural features that make the geodiversity of the Villages of the Region 3 BaJa CALifornia ANd the feasible to implement Sustainable aCtivities as a COMPLEMENT TO EXISTING. ONLY THE MOST IMPORTANT AREAS ARE INCLUDED FOR THEIR ACCESSIBILITY.

\begin{tabular}{|c|c|c|c|c|c|}
\hline Poblado & Atributos paisajísticos & Atributos culturales & Vegetación & $\begin{array}{c}\text { Actuaciones } \\
\text { humanas }\end{array}$ & $\begin{array}{c}\text { Potencial de } \\
\text { aprovechamiento }\end{array}$ \\
\hline El Rosario & $\begin{array}{c}\text { Afloramientos de rocas } \\
\text { sedimentarias del Cretácico, } \\
\text { Paleoceno, Plioceno y Pleis- } \\
\text { toceno. Fósiles de inverte- } \\
\text { brados marinos, dinosaurios } \\
\text { y plantas. Morfología de } \\
\text { tierras malas. Costa rocosa y } \\
\text { playas arenosas con dunas. }\end{array}$ & $\begin{array}{l}\text { Numerosos sitios prehis- } \\
\text { tóricos con talleres líticos, } \\
\text { concheros, corralitos } \\
\text { de piedra y grabados } \\
\text { rupestres. Ruinas de dos } \\
\text { sitios misionales y minas } \\
\text { abandonadas. }\end{array}$ & $\begin{array}{l}\text { Matorral costero. } \\
\text { Transición al } \\
\text { Desierto Central. }\end{array}$ & $\begin{array}{l}\text { Ganadería, mi- } \\
\text { nería, agricultura } \\
\text { de temporal y de } \\
\text { riego muy local. }\end{array}$ & $\begin{array}{l}\text { Geoturismo, tu- } \\
\text { rismo arqueoló- } \\
\text { gico e histórico, } \\
\text { turismo minero, } \\
\text { ecoturismo, } \\
\text { senderismo. }\end{array}$ \\
\hline $\begin{array}{l}\text { Laguna } \\
\text { Chapala }\end{array}$ & $\begin{array}{c}\text { Comprende dos lagos secos } \\
\text { del Pleistoceno y principios } \\
\text { del Holoceno. }\end{array}$ & $\begin{array}{l}\text { Sitios arqueológicos del } \\
\text { Holoceno temprano. } \\
\text { Rancho de finales del } \\
\text { siglo XIX. }\end{array}$ & $\begin{array}{l}\text { Una de las zonas } \\
\text { más áridas del } \\
\text { Desierto Central, } \\
\text { vegetación escasa. }\end{array}$ & Ganadería. & $\begin{array}{l}\text { Geoturismo y } \\
\text { turismo arqueo- } \\
\text { lógico. }\end{array}$ \\
\hline Cataviña & $\begin{array}{c}\text { Paisaje dominado por } \\
\text { grandes bloques de granito y } \\
\text { derrames de basalto. }\end{array}$ & $\begin{array}{l}\text { Pintura rupestre policroma } \\
\text { del tipo cochimí abstracto, } \\
\text { ruinas de la misión de San- } \\
\text { ta María de Los Ángeles } \\
\text { y cercanas a las de San } \\
\text { Fernando Velicatá. }\end{array}$ & $\begin{array}{l}\text { Matorral sarco- } \\
\text { crasicaule y de- } \\
\text { sértico rosetófilo, } \\
\text { abunda el cirio, } \\
\text { cardón y arroyos } \\
\text { con palmera azul. }\end{array}$ & $\begin{array}{l}\text { Ganadería y pesca } \\
\text { en la costa. Turis- } \\
\text { mo escaso. }\end{array}$ & $\begin{array}{l}\text { Turismo arqueo- } \\
\text { lógico e históri- } \\
\text { co, senderismo, } \\
\text { campismo. }\end{array}$ \\
\hline $\begin{array}{c}\text { Santa } \\
\text { Rosalita }\end{array}$ & $\begin{array}{c}\text { Extensa playa arenosa } \\
\text { con puntas rocosas, dunas } \\
\text { costeras. }\end{array}$ & Concheros arqueológicos. & $\begin{array}{l}\text { Parte costera del } \\
\text { Desierto Central, } \\
\text { vegetación desér- } \\
\text { tica arbustiva. }\end{array}$ & $\begin{array}{c}\text { Infraestructura } \\
\text { abandonada } \\
\text { impactando el } \\
\text { paisaje. Actividad } \\
\text { pesquera y turísti- } \\
\text { ca asociada a los } \\
\text { recursos marinos. }\end{array}$ & $\begin{array}{l}\text { Turismo de } \\
\text { playa, pesca } \\
\text { deportiva. }\end{array}$ \\
\hline $\begin{array}{l}\text { Punta } \\
\text { Prieta }\end{array}$ & $\begin{array}{l}\text { Valle ubicado en la con- } \\
\text { fluencia de dos sierras con } \\
\text { lomeríos, colinda al este } \\
\text { con una planicie aluvial con } \\
\text { lomeríos. Afloramientos de } \\
\text { rocas graníticas y volcáni- } \\
\text { cas. Tinajas en granito con } \\
\text { agua permanente. }\end{array}$ & $\begin{array}{l}\text { Pintura rupestre y sende- } \\
\text { ros prehistóricos en las } \\
\text { cercanías. Minas aban- } \\
\text { donadas. }\end{array}$ & $\begin{array}{c}\text { Matorral sarco- } \\
\text { crasicaule. Espec- } \\
\text { taculares paisajes } \\
\text { de cirios y cardón. } \\
\text { Arroyos con } \\
\text { palmeras. }\end{array}$ & $\begin{array}{c}\text { Ganadería y } \\
\text { minería. }\end{array}$ & $\begin{array}{l}\text { Ecoturismo, geo- } \\
\text { turismo minero, } \\
\text { senderismo, } \\
\text { campismo. }\end{array}$ \\
\hline $\begin{array}{c}\text { Nuevo } \\
\text { Rosarito }\end{array}$ & $\begin{array}{l}\text { Se encuentra sobre lomerío } \\
\text { ramificado con cañadas, } \\
\text { colinda al este con mesetas } \\
\text { basálticas con lomeríos y al } \\
\text { norte por dos sierras bajas. }\end{array}$ & $\begin{array}{l}\text { Pinturas y grabados } \\
\text { rupestres, senderos y } \\
\text { campamentos estacionales } \\
\text { prehistóricos. Acceso a la } \\
\text { misión de San Borja. }\end{array}$ & $\begin{array}{l}\text { Matorral sarco- } \\
\text { cracicaule. Abun- } \\
\text { da el cirio y el } \\
\text { cardón. }\end{array}$ & $\begin{array}{c}\text { Ganadería y } \\
\text { minería. }\end{array}$ & $\begin{array}{l}\text { Ecoturismo, } \\
\text { turismo arqueo- } \\
\text { lógico e históri- } \\
\text { co, geoturismo } \\
\text { minero, senderis- } \\
\text { mo, campismo. }\end{array}$ \\
\hline $\begin{array}{l}\text { Villa de } \\
\text { Jesús } \\
\text { María }\end{array}$ & $\begin{array}{l}\text { Llanura desértica con exten- } \\
\text { sos campos de dunas, salinas } \\
\text { y humedales. Paisaje que } \\
\text { resalta por su relieve plano. } \\
\text { Extensas playas arenosas. }\end{array}$ & $\begin{array}{l}\text { Concheros arqueológicos, } \\
\text { minas abandonadas y } \\
\text { sitios con pintura rupestre. }\end{array}$ & $\begin{array}{l}\text { Vegetación haló- } \\
\text { fita y de desiertos } \\
\text { arenosos. }\end{array}$ & $\begin{array}{l}\text { Agricultura en } \\
\text { pequeña escala, } \\
\text { pesca, y también } \\
\text { acuícola. Poca } \\
\text { afluencia turística. }\end{array}$ & $\begin{array}{c}\text { Ecoturismo, } \\
\text { geoturismo } \\
\text { minero, senderis- } \\
\text { mo, pesca depor- } \\
\text { tiva, campismo, } \\
\text { kayak y deportes } \\
\text { acuáticos. }\end{array}$ \\
\hline
\end{tabular}




\section{DISCUSIÓN}

El inventario de recursos geológicos de las tres regiones geomorfológicas que componen el Estado de Baja California, aun cuando se presentan los sitios que se consideran más importantes, testimonian la gran riqueza de atributos de su paisaje. La singularidad de estos escenarios es que en su mayoría aún se encuentran en excelente estado de conservación y que grandes extensiones del territorio se encuentran bajo algún esquema de protección, como es el caso del Valle de Los Cirios decretado como área natural protegida en 1980, cuyas 2.421.776 hectáreas la convierten en el área de protección de flora y fauna más grande del México (MINCH et al. 2003). En este sentido, es relevante mencionar que su definición se ha realizado con base en las cualidades abióticas del paisaje, sin considerar los abundantes atributos geológicos relevantes, o geopatrimonio, que requieren ser reconocidos. El patrimonio geológico es un concepto reciente que involucra todos los elementos abióticos que posean un valor cultural, científico, educativo, paisajístico y recreativo, y de gran importancia para estudiar e interpretar la evolución de la historia geológica de una región, o de la Tierra (DURÁN et al. 2005). $\mathrm{Su}$ reconocimiento requiere valorar la geodiversidad, ya que además de la conservación integral de todos los atributos del paisaje, tanto natural como cultural, ofrece la posibilidad de promover un aprovechamiento ecoturístico, ya que tradicionalmente éste se ha sesgado hacia la biodiversidad, en tanto que los atributos culturales lo determinan espacios muy pequeños, poco conocidos y valorados, y de escasa difusión.

Por tanto, bajo el concepto de geodiversidad, es posible que dentro de las áreas naturales protegidas, y las que aún no cuenten con un esquema de protección, se puedan integrar todos los recursos naturales bióticos y abióticos, así como los culturales, con el fin de impulsar un desarrollo sustentable en las comunidades rurales, poseedoras de gran parte de estos paisajes, los cuales han permanecido por décadas sin generar beneficios económicos. A ello contribuye que hoy día se ha despertado un creciente interés mundial hacia el turismo de aventura, científico y cultural, lo que abre un nicho de oportunidades para impulsar esta actividad económica, no solo en el Estado de Baja California, sino en toda la península. Para ello, además del inventario, es importante darle valor a la geodiversidad para identificar áreas prioritarias de conservación, así como los sitios de mayor potencial para su promoción y desarrollo. En este aspecto, la valoración de la geodiversidad es imprescindible, ya que se ha demostrado que no considerar la naturaleza abiótica del paisaje, ha llevado a la construcción de obras en sitios de alto valor geológico, como ocurre en la cuenca de Xingú en Brasil (SILVA et al. 2013), donde el área más geodiversa es donde se seleccionó la edificación de la obra.

El inventario realizado, basado en los atributos más relevantes del Estado de Baja California, pone en relieve que éste es muy geodiverso y con un gran potencial para implementar actividades productivas que giren alrededor de la conservación de su paisaje, lo cual no se centra sólo en la oferta ecoturística de visitas guiadas, hospedaje o actividades varias, o en la creación de pequeñas industrias fincadas en la explotación sustentable de los recursos naturales, como la elaboración de alimentos con base a productos del desierto o artesanías manufacturadas con materias primas del entorno, lo cual se pudo observar que sólo se hace de forma incipiente o con fines de autoconsumo (Fig. 12). 


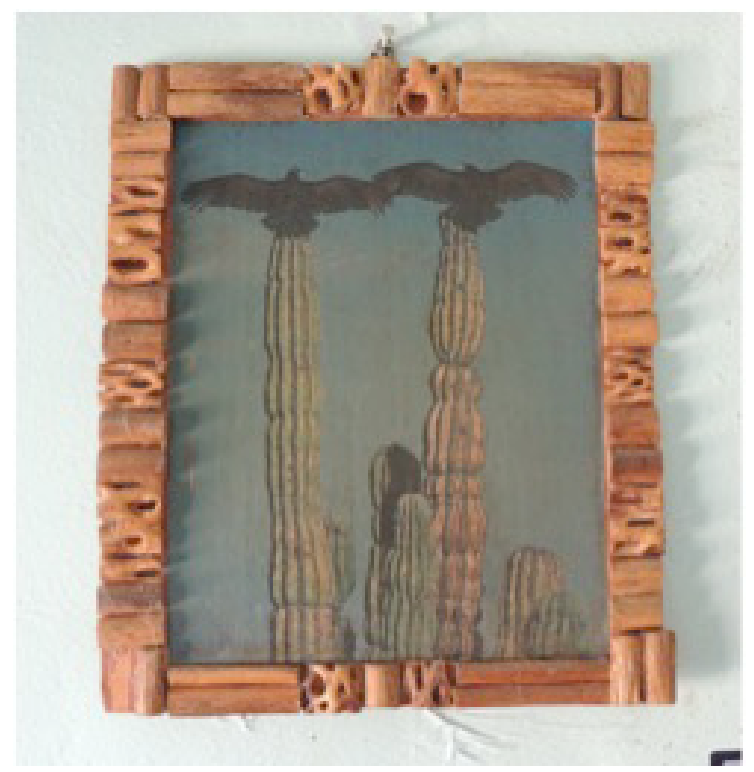

Fig. 12. Un ejemplo del uso sustentable de los recursos naturales.

Fig. 12. An example of sustaintble use of natural resources.

Por otro lado, la implementación de estas actividades económicas abre la posibilidad de promover la creación de geoparques, una figura de conservación que conlleva la valoración del total de los atributos del paisaje, y que cuando se incorporan actividades productivas que integren a las comunidades locales pueden ser promovidos a formar parte de la Red Global de Geoparques de la UNESCO. En este contexto, también se creó la Red Europea de Geoparques, la cual es un buen ejemplo de cómo el conocimiento científico natural y cultural puede ser socializado y transferido en la promoción y el aprovechamiento sustentable de estos recursos en beneficio de las comunidades locales (ZOUROS 2004; 2005; DOWLING \& NEWSOME 2006). Estas iniciativas son las que han llevado a una creciente aceptación de la geodiversidad como un criterio esencial en la gestión del territorio.

En este contexto, dado lo geodiverso del Estado de Baja California, el excelente estado de conservación de los escenarios naturales, la pobre promoción de los paisajes rurales como atractivos turísticos y el escaso apoyo a los habitantes de estas áreas, la creación de geoparques ofrece una alternativa para que la protección y conservación de los paisajes se traduzca en una opción de ingreso económico para ellos, $\sin$ las restricciones que existen para el caso de los otros esquemas de protección de los entornos naturales, donde las actividades económicas no están permitidas, o no se encuentran dentro de las áreas naturales protegidas. En el primer caso está la Reserva de la Biósfera del Alto Golfo de California y Delta del Río Colorado, donde en la zona núcleo, en los alrededores de su desembocadura, existen espectaculares cheniers. Estos son cordilleras paralelas a la línea de costa separadas por planicies lodosas, de 1 a $6 \mathrm{~m}$ de alto y longitud variable, y en el caso particular del Delta del Colorado se compone de hasta más del $90 \%$ de conchas de moluscos principalmente. Su singularidad, de ser un rasgo geomorfológico único en la península de Baja California, le confiere un alto valor paisajístico, educativo y didáctico, y consecuentemente, un atractivo turístico 
potencial en un área donde actividades económicas como la pesca no están permitidas. Sin embargo, fuera de esta zona y la de amortiguamiento, se encuentran rasgos geológicos y culturales que no han sido promovidos a pesar de su alto valor geoturístico, como el caso de la Sierra El Mayor, cuyo atractivo, además de ser un ramal del río Colorado, son sus rasgos tectónicos, vestigios arqueológicos y ser un geosímbolo para la etnia Cucapá, aspectos que no han sido explotados turísticamente, no obstante que en las áreas vecinas hasta un $58 \%$ de los visitantes locales lo hacen con fines recreativos (SANJURJO \& ISLAS 2007).

Otro caso es el de la sierra de San Pedro Mártir, donde el área protegida no incluye el rasgo geológico más importante de la montaña el Picacho del Diablo, el cual es el atractivo de escalada más importante del Estado, y a pesar del concurrido número de visitantes nacionales y extranjeros, no existe ningún instrumento de gestión para el aprovechamiento turístico del área por parte de los propietarios de los predios, que incluye rasgos tectónicos, yacimientos minerales, pinturas y petrograbados prehistóricos, cañones y cascadas, entre otros atractivos, además de su biodiversidad. En ambos casos, la figura de un geoparque sería un esquema apropiado para promover, a través de la conservación, actividades económicas sustentables en los medios rurales, primordialmente turísticas y recreativas, además de incentivar pequeñas industrias de producción basadas en la elaboración de artesanías con recursos naturales de la región.

Por tanto, aun cuando este trabajo constituye un primer análisis exploratorio de la geodiversidad, pone en relieve el alto potencial de aprovechamiento turístico de los recursos naturales y culturales del Estado, que amerita estudios más profundos para diseñar instrumentos de gestión en los que se incorpore este concepto.

\section{CONCLUSIONES}

Ante el panorama mundial de la creciente incorporación de la geodiversidad como instrumento de gestión en el manejo sustentable del territorio, es inaplazable incorporarla para un manejo más eficiente de los recursos naturales y culturales del Estado de Baja California, particularmente porque gran parte del territorio cuenta con recursos naturales y culturales en muy buen estado de conservación.

Aunque buena parte del Estado posee áreas naturales protegidas, la creación de geoparques constituye una figura de conservación atractiva, ya que incorporar a las comunidades locales en actividades económicas sustentables permite un desarrollo fincado esencialmente en el aprovechamiento de los atributos naturales para los servicios ecoturísticos y culturales, así como el desarrollo de mercados artesanales propios de la región. En la sierra de San Pedro Mártir y en el delta del río Colorado, dada su geodiversidad y cercanía a los centros urbanos, rasgos de importancia geológica y cultural, y desde que no es área protegida, la creación de geoparques sería atractiva para incorporar a las comunidades locales en actividades económicas que representen el paisaje y su conservación.

\section{AGRADECIMIENTOS}

La primera autora agradece al CONACYT el otorgamiento de la beca de posgrado de la que derivó esta investigación, así como a la UABC por las facilidades logísticas para el trabajo de campo, al igual que a los demás autores por el apoyo brindado a lo largo del proyecto. 


\section{REFERENCIAS}

AGUIRRE BERNAL, C., 1987. Breve historia del estado de Baja California. Ediciones Quinto Sol: 206 p.

ALLISON, E. C., 1970. Pacific slope geology of northern Baja California and adjacent Alta California geological society of Economic Paleontologists and Mineralogists, and the Society of Economic [i.e. Exploration]. Geophysicists. Ensenada, Baja California, México: 160 p.

ALLISON, E.C., 1974. The type Allisitos Formation (Cretaceous, Aptian-Albian) of Baja California and its bivalve fauna. In: GASTIL, G. \& LILLEGRAVEN, J. (Eds.), Geology of Peninsular California: Los Ángeles, California, Am Assoc of Pet Geol Pacific Section: 20-59.

AMORÓS ZAVALA, T., 2011. Planeación para el desarrollo regional sustentable con la incorporación del turismo en el corredor costero San Felipe - San Luis Gonzaga, Baja California, México (1988-2008). Maestría en Ingeniería Civil, Instituto Politécnico Nacional, Zacatenco. Inédito: 205 p.

BRILHA，J. B. R., 2005. Patrimonio Geológico e Geoconservacao: a conservacao da naturaleza na sua vertente geológica. Braga.

BRUSCHI, V. M., 2007. Desarrollo de una metodología para la caracterización, evaluación y gestión de los recursos de la geodiversidad. Tesis de Doctorado, Universidad de Cantabria, Santander. Inédito: $671 \mathrm{p}$.

CARCAVILLA URQUí, L., DURÁN VALSERO, J. J. \& LÓPEZ PORTILLO, J., 2008. Geodiversidad: concepto y relación con el patrimonio geológico. GeoTemas, 10: 1299-1303.
DEL RAMO JIMÉNEZ, A., GUILLÉN MANDÉJAR, F. \& COY GÓMEZ, E., 2003. La geodiversidad: un componente esencial en las estrategias para la conservación del medio natural, su relación con la biodiversidad. In: I. RABANO, I. MANTECA \& C. GARCÍA (Eds.), Patrimonio Geológico y Minero y Desarrollo Regional. IGME: 97-106.

DELGADILLO, J., 1998. Florística y ecología del norte de Baja California. Ensenada, B.C. UABC: 454 p.

DELGADO ARGOTE, L. A., 2000. Evolución tectónica y magmatismo Neógeno de la Margen Oriental de Baja California Central. Tesis de Doctorado, UNAM, México. Inédito: 194 p.

DEMERÈ, T. A., ROEDER, M. A., CHANDLER, R. M. \& MINCH, J. A., 1984. Paleontology of the Middle Miocene Los Indios Member of the Rosarito Beach Formation, Northwestern Baja California, México. In: J. MINCH \& J. ASHBY (Eds.), Miocene and Cretaceous Depositional Environments, Northwest Baja California, México: 47-56.

DOWLING, R. \& NEWSOME, D., 2006. Geotourism. Elsevier, Oxford: 352 p.

DURÁN VALSERO, J. J., CARCAVILLA URQUÍ, L. \& LÓPEZ-MARTÍNEZ, J., 2005. Patrimonio geológico: Una panorámica de los últimos 30 años en España. Bol. R. Soc. Hist. Nat. (Sec. Geol.), 100(1-4): 277-287.

ELDER, W. A., BIRD, D. K., WILLIAM, A. E. \& SCHIFFMAN, P., 1984. Hydrothermal-flow regime and magmatic heat source of the Cerro Prieto geothermal system, Baja California, México. Geothermics, 13: 27-47. 
FRIZZELL, V. A. J., 1984. The geology of the Baja California peninsula: an introduction. In: V. A. J. FRIZZELL (Ed.), Geology of the Baja California Peninsula. Pacific Section S.E.P.M.: 1-7.

GAITÁN MORÁN, J. \& ÁlVAREZ ARELLANO, A., 2009. The protection and use of the geological and paleontological heritage in Baja California Sur, México. Carnet de Geologie, 3: 35-48.

GASTIL, G. R., PHILliPS, R. P. \& ALLISON, E. C., 1975. Reconnaissance Geology of the State of Baja California. Boulder, Colorado. The Geological Society of America, Inc. Memoir 140: 92 p.

GRAY, M., 2004. Geodiversity valuing and conserving abiotic nature. Great Britain: John Eiley \& Sons Ltd: 450 p.

GUTIÉRREZ-NEGRÍN， C. A. \& QUIJANO-LEÓN, J. L., 2004. Update of Geothermics in Mexico. Geotermia. Revista Mexicana de Geoenergía, 17(1): 21-30.

HOSE, T. A., 2000. European geoturismgeological interpretation and geoconservation promotion for tourists. In: D. BARETTINO, W. A. P. WIMBLEDON \& E. GALLEGO VALCARCE (Eds.), Geological heritage: its conservation and management. Instituto Tecnológico Geominero de España, Madrid: 127-146.

KOZLOWSKI, S., 2004. Geodiversity: The concept and scope of geodiversity. Przeglad Geologiczny, 52: 833-837.

LIPPMANN, M. J., GOLDSTEIN, N. E., HALFMAN, S. E. \& WITHERSPOON, P. A., 1984. Exploration and development of the Cerro Prieto geothermal field. Journal of Petroleum Technology, 36(9): 1579-1591.

LÓPEZ, T. G. \& MATA, J. N., 2002. Baja California: escenarios para el nuevo milenio. Universidad Nacional Autónoma de México, Centro de Investigaciones Interdisciplinarias en Ciencias y Humanidades: 4521 p.
MARTÍN-BARAJAS， A., TÉLLEZDUARTE, M.A.\& RENDÓN-MÁRQUEZ, G., 1993. Sedimentary environments of the Late Neogene Puertecitos Marine Sequence, Northeastern Baja California. Geologic Investigations in Baja California, México. Annual Fieltrip guidebook No. 21, South Coast Geological Society, 21: 90-114.

MARTÍNEZ, O. R., 2008. Patrimonio geológico. Identificación, valoración y gestión de sitios de interés geológico. Geograficando, 4(4): 233-250.

McKIRDY, A. P., THREADGOULD, R. \& FINLAY, J., 2001. Geoturism: an emerging rural development opportunity. In: J. E. GORDON \& K. F. LEYS (Eds.), Earth Science and the Natural Heritage. Internations and Integrated Management. The Stationery Office: 255-261.

MINCH, J. A., 1967. Stratigraphy and structure of the Tijuana-Rosarito Beach area, northwestern Baja California, México. Geol. Soc. of Amer. Bull, 78: 1155-1177.

MINCH, J. A., ASHBY, J., DEMERE, T. A. \& KUPER, H. T., 1984. Correlation and depositational environments of the middle Miocene Rosarito Beach Formation of Northwestern Baja California, México. In: J. A. MINCH \& J. ASHBY (Eds.), Miocene and Cretaceous Depositional Environments, Northwestern Baja California, México. Pacific Section A.A.P.G.: 54: 33-46.

MINCH, J. A., MINCH, E., MINCH, J. \& LEDESMA-VÁZQUEZ, J., 2003. Caminos de Baja California. Geología y biología para su viaje. John Minch and Associates, Inc.: 186 p.

MORRIS, W. J., 1967. Baja California: late Cretaceous dinosaurs. Science, 155(3769): 1539-1541.

MORRIS, W. J., 1971. Mesozoic and Tertiary vertebrates in Baja California. National Geographic Society. Research Reports, 1965: 195-198. 
MOLES, N. R. \& MOLES, R. T., 2004. Geodiversity as an explanation for geodiversity in the Burren National Park. In: M. PARKES (Ed.), Natural and cultural landscapes. Dublin: The geological foundation: Royal Irish Academy: 61-64.

NIETO, L. M., 2001. Geodiversidad: propuesta de una definición integradora. Boletín Geológico y Minero, 112(2): 3-12.

NIETO, L. M., 2002. Patrimonio geológico, cultural y turismo. Boletín del Instituto de Estudios Giennenses, 182: 109-122.

NIETO, L. M., PÉREZ LORENTE, F., GUILLÉN MONDÉJAR, F. \& DÍAZ MARTÍNEZ, E., 2006. Estado actual de la legislación para la geoconservación en España. Trabajos de Geología, 26: 187-201.

NOVACEK, M. J., FERRUSQUÍAVILLAFRANCA, I., FLYNN, J. J., WYSS, A. R. \& NORRELL, M. A., 1991. Wasatchian (early Eocene) mammals and other vertebrates from Baja California, México: the Lomas Las Tetas de Cabra fauna. Bulletin of the American Museum of Natural History no. 208, 92 p.

OCHOA ZAZUETA, J. Á., 1980. El origen del Río Colorado, el Golfo de California y el Valle de Mexicali en la tradición nativa cucapá. Calafia, IV(2): 51-76.

ORTEGA-RIVERA, M. A., 2000. ¿Y qué edad tiene esa Roca?. Paper presented at the X Congreso Nacional de Geoquímica, Temixco, Morelos, México. Inédito, 6(1): 93-104.

PEREIRA, D., PEREIRA, P., BRILHA, J. \& SANTOS, L., 2013. Geodiversity assessment of Paraná State (Brazil): an innovative approach. Environmental Management, 52: 541-552.

PIACENTE, S. \& CORATZA, P., 2005. Geomorphological sites and Geodiversity. 18(1): $322 \mathrm{p}$.
PROSSER, C. D., BRIDGLAND, D. R., BROWN, E. J. \& LARWOOD, J. G., 2011. Geoconservation for science and society: challenges and opportunities. Proc Geol Assoc, 122: 337-342.

PUY y ALQUIZA, M. J., MIRANDA AVILÉS, R.\& CAUDILLO GONZÁLEZ, M., 2010. Propuesta de puntos de interés geológico y minero en el Área Natural Protegida El Orito. Distrito Minero de Guanajuato, México. PASOS Revista de Turismo y Patrimonio Cultural, 8(4): 595607.

RITTER, E. W., 1998. Investigations of prehistoric behavioral ecology and culture change within the Bahia de los Angeles Region, Baja California. Pacific Coast Archaeological Society Quarterly, 34(3): 9-44.

RZEDOWSKI, J., 1978. La vegetación de México. México: Limusa: 504 p.

SANJURJO RIVERA, E. \& ISLAS CORTÉS, I., 2007. Valoración económica de la actividad recreativa en el río Colorado. Región y Sociedad, XIX (40): 147-172.

SANTILLÁN, M. \& BARRERA, T., 1930. Las posibilidades petrolíferas en la Costa Occidental de Baja California, entre los paralelos 30 y 32 de latitud norte. Anales del Instituto Geológico de México: pp. 1-37.

SANTUCCI, V. L., 2005. Historical Perspectives on Biodiversity and Geodiversity. Geodiversity \& Geoconservation, 22(3): 29-34.

SARYCHIKHINA, O., GLOWACKA, E., MELLORS, R. \& VIDAL, F. S., 2011. Land subsidence in the Cerro Prieto Geothermal Field, Baja California, México, from 1994 to 2005: An integrated analysis of DINSAR, leveling and geological data. J Volcanol \& Geother Res, 204 (1-4): 76-90. doi: 10.1016/j.jvolgeores.2011.03.004. 
SEDLOCK, R. L., 2003. Geology and tectonic of the Baja California peninsula and adjacent areas. In: S. E. JOHNSON, S. R. PATERSON, J. M. FLETCHER, G. H. GIRTY, D. L. KIMBROUGH \& A. MARTÍN-BARAJAS (Eds.), Tectonic evolution of northwestern Mexico and the southwestern USA: Boulder, Colorado. Geological Society of America Special Paper: 374: 1-42.

SILVA, C. R. D., 2008. Geodiversidade do Brasil: conhecer o passado, para entender o presente e prever o futuro. Rio de Janeiro: CPRM: 264 p.

SILVA, J. P., PEREIRA, D., AGUIAR, A. M. \& RODRIGUES, C., 2013. Geodiversity assessment of the Xingu drainage basin. J. Maps, 9: 1-9.

STANLEY, M., 2000. Geodiversity. Earth Heritage, 14: 15-18.

STOCK, J., 1997. Efectos geológicos de la tectónica de placas Miocénica a Reciente en la península de Baja California. Memorias de la IV Reunión Internacional sobre geología de la Península de Baja California, Ensenada, B.C., del 6 al 9 de abril. Inédito, s/p.

SUÁREZ-VIDAL， F., MENDOZABORUNDA, R., NAVARRETEZAMARRIPA, L., RAMÍREZ, J. \& GLOWACKA, E., 2008. Shape and dimensions of the Cerro Prieto pull-apart basin, Mexicali, Baja California, México, based on the regional seismic and surface structures. International Geology Review, 50(7): 636-649.

TAPIA LANDEROS, A., 2002. Baja California. Descripción del medio natural. Material didáctico para el curso Derecho Ecológico: $21 \mathrm{p}$.
TÉLlEZ DUARTE, M. A., 1993. Arqueología y paleontología: un recurso cultural en Baja California. Memorias del Ciclo de Conferencias 1993 del Seminario de Historia de Baja California. Ensenada, Baja California, SHBC e IIH-UABC: pp. 65-76.

TERRA PENINSULAR, 2004. Un león de montaña errante marca la importancia del trabajo de Terra Peninsular en el borde de las dos Californias. http://terrapeninsular. blogspot.mx/2011_11_01_archive.html.

ULLOA, R., TORRE, J., BOURILLÓN, L., GONDOR, A. \& ALCANTAR, N., 2006. Planeación Ecorregional para la conservación marina: Golfo de California y costa occidental de Baja California Sur. Informe final a The Nature conservancy. Guaymas Comunidad y Biodiversidad, A.C.: 153 p.

UNESCO, 1999. UNESCO Geoparks Programme. Proc. $156^{\text {th }}$ Session of UNESCO Executive Board, 156 Ex/11. Paris, France.

WATANABE, T., 2005. Geodiversity: necessary of its conservation and research in Japan. Global Environment Research, 10: 125-126.

WHITE, C. A., 1885. On new Cretaceous fossils from California. U.S. Geol. Survey Bull., 32: 1762-1807.

ZOUROS, N., 2004. The European Geoparks Network. Geological heritage protection and local development. Episodes 27(3): 165-171.

ZOUROS, N., 2005. Assessment, protection and promotion of geomorphological and geological sites in the Aegean area, Greece. Geomorphol relief processus environnement 3: 227-234. 